Wright State University

CORE Scholar

$9-1-2010$

\title{
Deep Traps in AlGaN/GaN Heterostructures Studied by Deep Level Transient Spectroscopy: Effect of Carbon Concentration in GaN Buffer Layers
}

\author{
Z-Q. Fang \\ B. Claflin \\ David C. Look \\ Wright State University - Main Campus, david.look@wright.edu \\ D. S. Green \\ R. Vetury
}

Follow this and additional works at: https://corescholar.libraries.wright.edu/physics

Part of the Physics Commons

\section{Repository Citation}

Fang, Z., Claflin, B., Look, D. C., Green, D. S., \& Vetury, R. (2010). Deep Traps in AIGaN/GaN

Heterostructures Studied by Deep Level Transient Spectroscopy: Effect of Carbon Concentration in GaN Buffer Layers. Journal of Applied Physics, 108 (6), 63706.

https://corescholar.libraries.wright.edu/physics/166

This Article is brought to you for free and open access by the Physics at CORE Scholar. It has been accepted for inclusion in Physics Faculty Publications by an authorized administrator of CORE Scholar. For more information, please contact library-corescholar@wright.edu. 


\title{
Deep traps in AIGaN/GaN heterostructures studied by deep level transient spectroscopy: Effect of carbon concentration in GaN buffer layers
}

\author{
Z.-Q. Fang, ${ }^{1, a)}$ B. Claflin, ${ }^{1}$ D. C. Look, ${ }^{1}$ D. S. Green, ${ }^{2}$ and R. Vetury ${ }^{2}$ \\ ${ }^{1}$ Semiconductor Research Center, Wright State University, Ohio 45435, USA and Materials and \\ Manufacturing Directorate, Air Force Research Laboratory, Wright Patterson AFB, Ohio 45433, USA \\ ${ }^{2}$ Defense and Power, RF Micro Devices, Inc., Charlotte, North Carolina 28269, USA
}

(Received 19 April 2010; accepted 1 August 2010; published online 17 September 2010)

\begin{abstract}
Electrical properties, including leakage currents, threshold voltages, and deep traps, of AlGaN/GaN heterostructure wafers with different concentrations of carbon in the GaN buffer layer, have been investigated by temperature dependent current-voltage and capacitance-voltage measurements and deep level transient spectroscopy (DLTS), using Schottky barrier diodes (SBDs). It is found that (i) SBDs fabricated on the wafers with GaN buffer layers containing a low concentration of carbon (low-[C] SBD) or a high concentration of carbon (high-[C] SBD) have similar low leakage currents even at $500 \mathrm{~K}$; and (ii) the low-[C] SBD exhibits a larger (negative) threshold voltage than the high-[C] SBD. Detailed DLTS measurements on the two SBDs show that (i) different trap species are seen in the two SBDs: electron traps $\mathrm{A}_{\mathrm{x}}(0.9 \mathrm{eV}), \mathrm{A}_{1}(0.99 \mathrm{eV})$, and $\mathrm{A}_{2}(1.2 \mathrm{eV})$, and a holelike trap $\mathrm{H}_{1}(1.24 \mathrm{eV})$ in the low-[C] SBD; and electron traps $\mathrm{A}_{1}, \mathrm{~A}_{2}$, and $\mathrm{A}_{3}(\sim 1.3 \mathrm{eV})$, and a holelike trap $\mathrm{H}_{2}(>1.3 \mathrm{eV})$ in the high-[C] SBD; (ii) for both SDBs, in the region close to GaN buffer layer, only electron traps can be detected, while in the AlGaN/GaN interface region, significant holelike traps appear; and iii) all of the deep traps show a strong dependence of the DLTS signal on filling pulse width, which indicates they are associated with extended defects, such as threading dislocations. However, the overall density of electron traps is lower in the low-[C] SBD than in the high-[C] SBD. The different traps observed in the two SBDs are thought to be mainly related to differences in microstructure (grain size and threading dislocation density) of GaN buffer layers grown at different pressures. (C) 2010 American Institute of Physics. [doi:10.1063/1.3488610]
\end{abstract}

\section{INTRODUCTION}

One of the major issues that limit the performance of AlGaN/GaN heterostructure field effect transistor (HFET) devices for next generation high-power and high-frequency electronics is the presence of electronic traps in the device structure. Early studies revealed that gate lag and drain current collapse in HFET devices were related to traps in the AlGaN surface and GaN buffer layers. ${ }^{1}$ Many techniques, such as photoionization spectroscopy, ${ }^{2}$ deep level transient spectroscopy (DLTS), ${ }^{3}$ deep level optical spectroscopy (DLOS), ${ }^{4,5}$ and current-DLTS on HFETs, ${ }^{6}$ have been used to study traps in AlGaN/GaN structures. Carbon is a common residual impurity in unintentionally doped (UID) GaN buffer layers grown by metalorganic chemical vapor deposition (MOCVD) but the carbon concentration and resistivity in these layers can be controlled by growth pressure. ${ }^{7}$ To increase the breakdown voltage and decrease drain leakage current of HFET devices, growth of GaN buffer layers with optimal resistivity and carbon concentration is necessary. In this work, we use temperature dependent current-voltage $(\mathrm{I}-\mathrm{V})$ and capacitance-voltage $(\mathrm{C}-\mathrm{V})$ measurements as well as DLTS measurements at different depths, different rate windows, and different filling pulse widths to investigate the effect of carbon concentration, [C], in the GaN buffer layer on deep traps in present in $\mathrm{AlGaN} / \mathrm{GaN}$ devices.

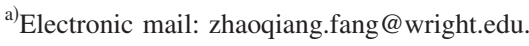

\section{EXPERIMENTAL}

The AlGaN/GaN heterostructure used in this study consisted of an AlN nucleation layer, an UID GaN buffer layer $(\sim 2 \mu \mathrm{m}$ thick), and an UID AlGaN layer $(\sim 22.5 \mathrm{~nm}$ thick), with an $\mathrm{Al}$ mole fraction of $25 \%$, all grown by MOCVD on a SiC substrate. The carbon concentration in the buffer layer was primarily controlled by growth pressure. Two wafers, one grown at 500 Torr and having a low [C] in the buffer layer and one grown at 100 Torr containing a high $[\mathrm{C}]$, were evaluated in this study. According to Wickenden et al. ${ }^{7}$ carbon incorporation decreases from $4 \times 10^{17}$ to 5 $\times 10^{16} \mathrm{~cm}^{-3}$ with an increase in growth pressure from 65 to 500 Torr. Each wafer was patterned with HFETs, Schottky barrier diodes (SBDs), and van der Pauw (VDP) structures and VDP and SBD samples were cut close to the center of each wafer for Hall-effect and DLTS measurements. Temperature-dependent (20-320 K) Hall-effect measurements were performed with a Lakeshore 7507 system and show similar electrical properties for samples with low- and high-[C]: mobility $\mu=6900 \mathrm{~cm}^{2} / \mathrm{V} \mathrm{s}$ and $1600 \mathrm{~cm}^{2} / \mathrm{V} \mathrm{s}$, and sheet charge concentration $\mathrm{n}=1 \times 10^{13} \mathrm{~cm}^{-2}$ and 9.6 $\times 10^{12} \mathrm{~cm}^{-2}$, at $20 \mathrm{~K}$ and $300 \mathrm{~K}$, respectively. In the SBD samples, Schottky dot (125 $\mu \mathrm{m}$ in diameter), and ringshaped Ohmic contact surrounding the dot were fabricated on the surface using $\mathrm{Ni} / \mathrm{Au}$ and $\mathrm{Ti} / \mathrm{Al} / \mathrm{Ni} / \mathrm{Au}$ metallizations, respectively. The $25 \mu \mathrm{m}$ region between the Schottky dot and Ohmic contact was passivated with $\mathrm{Si}_{3} \mathrm{~N}_{4}$. The C-V and DLTS measurements were carried out using an Accent 


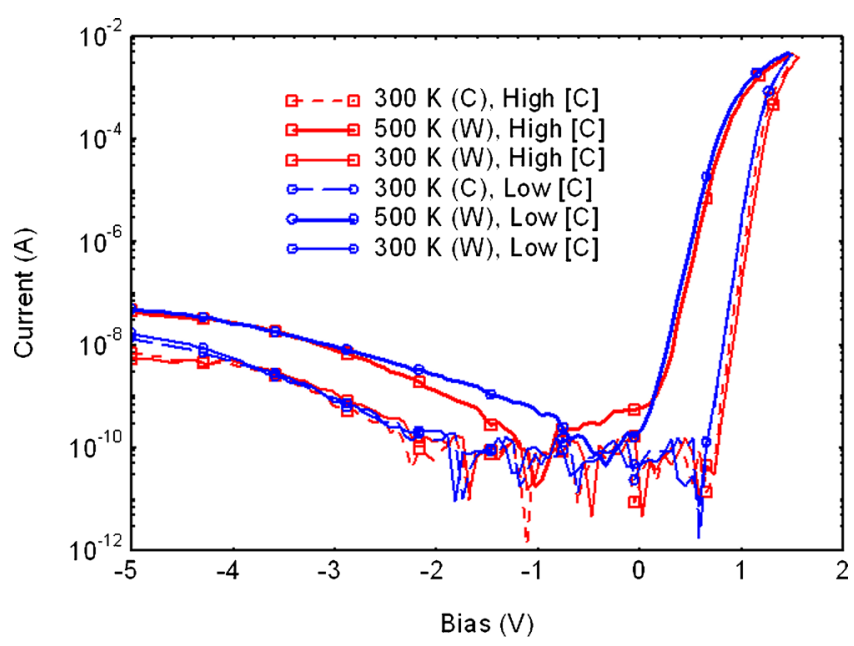

FIG. 1. (Color online) I-V characteristics, measured upon warming from 300 to $500 \mathrm{~K}$ and cooling to $300 \mathrm{~K}$ for high-[C] and low-[C] samples [symbols $(\mathrm{W})=$ warming and $(\mathrm{C})=$ cooling $]$.

DL8000 spectrometer, which is operated at $1 \mathrm{MHz}$, with a test signal of $100 \mathrm{mV}$. DLTS spectra were obtained from Fourier transformation of capacitance transients, measured over a transient period, as the temperature is swept from 300 to $550 \mathrm{~K}$. The $\mathrm{I}-\mathrm{V}$ measurements were conducted using a current amplifier incorporated into the spectrometer. Before any measurements of temperature dependent $\mathrm{I}-\mathrm{V}$ and $\mathrm{C}-\mathrm{V}$ characteristics were performed, the SBD samples were warmed to $500 \mathrm{~K}$ and then cooled to $300 \mathrm{~K}$ to avoid illumination effects from a microscope light which was used during sample mounting. To determine the location of traps in the AlGaN/GaN structure, DLTS measurements were performed at a constant bias $\left(\mathrm{U}_{\mathrm{R}}\right)$, but with different filling pulse heights $\left(\mathrm{U}_{\mathrm{P}}\right)$, corresponding to regions either close to the $\mathrm{GaN}$ buffer layer or $\mathrm{AlGaN} / \mathrm{GaN}$ interface. Different DLTS transient periods $\left(\mathrm{T}_{\mathrm{W}}\right)$ were used to determine the activation energies of major electron and hole traps. Finally, to determine whether a measured trap is related to extended defects, DLTS measurements were performed as a function of filling pulse width $\left(t_{p}\right)$. A logarithmic dependence of DLTS signal with $t_{p}$ indicates that a given trap is related to extended defects (e.g., threading dislocations). ${ }^{3}$

\section{RESULTS AND DISCUSSION}

Figures 1 and 2 present the I-V-T and C-V-T characteristics for the two SBDs, measured at 300 and $500 \mathrm{~K}$ upon warming and at $300 \mathrm{~K}$ upon cooling. From the I-V-T curves, we see that (i) the forward currents at 300 and $500 \mathrm{~K}$ for both SBDs increase exponentially with bias as expected for thermionic emission; (ii) the reverse leakage currents for both SBDs are quite low even at $500 \mathrm{~K}$. However, the high-[C] sample leakage is lower than that of the low-[C] sample at $300 \mathrm{~K}$ and is nearly constant for $\mathrm{U}_{\mathrm{R}}<-4 \mathrm{~V}$ [due to complete depletion of the two-dimensional electron gas (2DEG)] ; and (iii) the $300 \mathrm{~K} \mathrm{I-V}$ characteristics for both SBDs show good reproducibility before and after heating to $500 \mathrm{~K}$. However, as presented in Fig. 2, two differences in C-V-T characteristics are observed for these two samples. First, the 300 $\mathrm{K}$ C-V characteristics, measured upon warming and cooling,

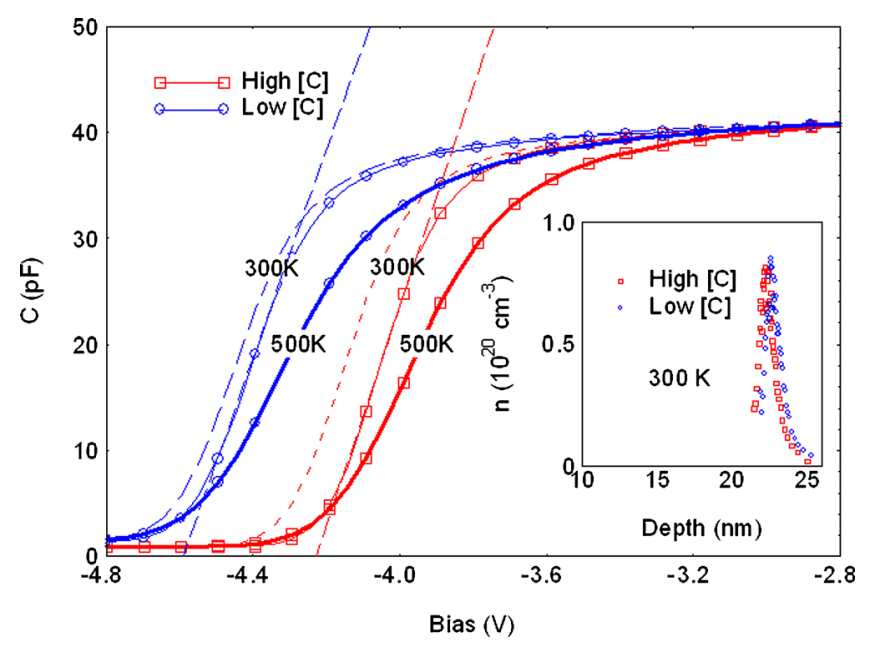

FIG. 2. (Color online) C-V characteristics, measured upon warming from 300 to $500 \mathrm{~K}$ and cooling to $300 \mathrm{~K}$, for high-[C] and low-[C] samples (at $300 \mathrm{~K}$, dashed lines= warming from $300 \mathrm{~K}$ and solid lines=cooling to $300 \mathrm{~K})$.

show remarkable change due to an illumination effect, i.e., a shift in the $300 \mathrm{~K}$ threshold voltage $\left(\mathrm{V}_{\text {th }}\right)$ by $\sim 0.05 \mathrm{~V}$ for the low-[C] SBD and by $\sim 0.1 \mathrm{~V}$ for the high-[C] SBD. The illumination effect arises because deep traps can be optically filled by the illumination at $300 \mathrm{~K}$ and thermally emptied by warming to $500 \mathrm{~K}$ or higher temperatures. Second, as compared to that of the high-[C] SBD, the low-[C] SBD shows a more negative $\mathrm{V}_{\text {th }}$ (by $\sim-0.4 \mathrm{~V}$ ), which is likely due to lower [C] and resistivity in the $\mathrm{GaN}$ buffer layer, grown at higher pressure. Variation in $\mathrm{V}_{\text {th }}$ with $\mathrm{GaN}$ buffer growth pressure has been reported for devices on the AlGaN/GaN heterostructures grown on $\mathrm{Si}$ substrates. ${ }^{16}$ In that study, it was found that the variation was about $0.5 \mathrm{~V}$ when the growth pressure changed from 200 to 760 Torr; however, at the lowest growth pressure (100 Torr), the $\mathrm{V}_{\text {th }}$ showed a large variation (about $2.5 \mathrm{~V}$ ). This variation was believed to be due to the variation in sheet carrier concentration. However, in this study, we find that variation in sheet carrier concentration in the two wafers is very slight (i.e., a little higher at 300 $\mathrm{K}$ in the low-[C] sample), which was further confirmed by similar 2DEG densities, deduced from $\mathrm{C}-\mathrm{V}$ characteristics. The shift in $\mathrm{V}_{\text {th }}$ might be due to a slight difference in the thickness of the AlGaN cap. As shown in the inset of Fig. 2, the 2DEG carrier density is about the same for both SBDs but there is a slight difference in thickness of the AlGaN cap (22.7 nm for the low-[C] SBD and $22.3 \mathrm{~nm}$ for the high-[C] $\mathrm{SBD})$. Another possible reason for the $\mathrm{V}_{\text {th }}$ shift might be the difference in density of shallow traps in the two SBD samples; i.e., there could be more shallow traps in the low-[C] sample than in the high-[C] sample. According to Kordos et al., ${ }^{8}$ the threshold voltage can be described as $\mathrm{V}_{\mathrm{th}}=\Phi_{\mathrm{b}}-\Delta \mathrm{E}_{\mathrm{c}}-\left(\mathrm{qn}_{\mathrm{tot}} \mathrm{d} / 2 \varepsilon_{\mathrm{r}} \varepsilon_{0}\right)$, where $\Phi_{\mathrm{b}}$ is the barrier height, $\Delta \mathrm{E}_{\mathrm{c}}$ is the conduction band discontinuity, $\mathrm{d}$ is the barrier-channel distance, and $\varepsilon_{\mathrm{r}} \varepsilon_{0}$ is the dielectric constant. The total carrier density $n_{\text {tot }}$ is a sum of the densities of shallow carriers and carrier traps, $n_{\text {tot }}=n_{\mathrm{s}}+n_{T}$. A shift in $V_{\text {th }}$ to a more negative value has been reported for the $\mathrm{AlGaN} /$ GaN SBDs after $1 \mathrm{MeV}$ electron-irradiation (EI), which is attributed to the EI-induced shallow traps. ${ }^{9}$ 

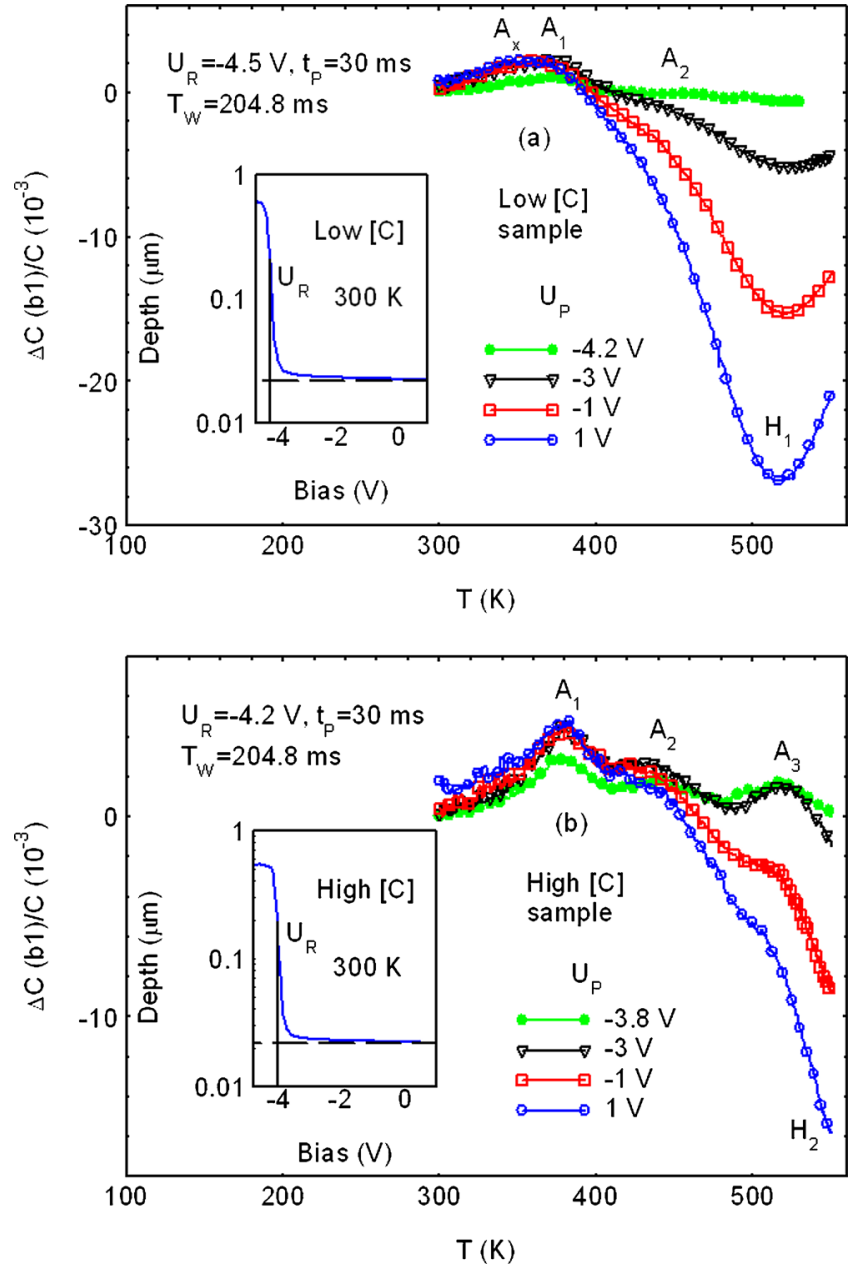

FIG. 3. (Color online) DLTS spectra as a function of filling pulse height $\left(\mathrm{U}_{\mathrm{P}}\right)$ (a) from 1 to $-4.2 \mathrm{~V}$, keeping $\mathrm{U}_{\mathrm{R}}=-4.5 \mathrm{~V}$, for the low-[C] sample and (b) from 1 to $-3.8 \mathrm{~V}$, keeping $\mathrm{U}=-4.2 \mathrm{~V}$, for the high-[C] sample.

Because of the different $\mathrm{V}_{\text {th }}$ observed in the two SBD samples, $\mathrm{U}_{\mathrm{R}}$ was selected differently $(-4.5 \mathrm{~V}$ for the low- $[\mathrm{C}]$ SBD and $-4.2 \mathrm{~V}$ for the high-[C] SBD) to ensure that DLTS measurements are made in the pinch-off region. DLTS spectra, measured as a function of $U_{P}$, while keeping reverse bias $\left(\mathrm{U}_{\mathrm{R}}\right)$ constant, are presented in Figs. 3(a) and 3(b) for the low-[C] and high-[C] SBDs, respectively. From the depth versus bias relationship, which is extracted from $\mathrm{C}-\mathrm{V}$ data and shown in the insets of Figs. 3(a) and 3(b), the corresponding depths for the two $\mathrm{U}_{\mathrm{R}}$ values chosen is about $0.15 \mu \mathrm{m}$. Three $\mathrm{U}_{\mathrm{P}}$ values were used for each $\mathrm{SBD}\left(\mathrm{U}_{\mathrm{P}}\right.$ $=1,-1,-3 \mathrm{~V}$ ) which corresponds to DLTS detection in regions close to and across the 2DEG channel (or AlGaN/GAN interface region). The fourth values, $\mathrm{U}_{\mathrm{P}}=-4.2 \mathrm{~V}$ for the low-[C] SBD and $\mathrm{U}_{\mathrm{P}}=-3.8 \mathrm{~V}$ for the high-[C] SBD, corresponds to DLTS detection only in the pinch-off region close to the GaN buffer layer. From Figs. 3(a) and 3(b), we see (i) electron traps $A_{x}, A_{1}$, and $A_{2}$ at $U_{P}=-4.2 \mathrm{~V}$ in the low- $[C]$ SBD; (ii) electron traps $A_{1}, A_{2}$, and $A_{3}$ at $U=-3.8 \mathrm{~V}$ in the high-[C] SBD; and (iii) overall trap densities are higher in the high-[C] SBD than in the low-[C] SBD, but not for $\mathrm{H}$ traps. As $U_{p}$ increases to $-3 \mathrm{~V}$, corresponding to detection near the 2DEG channel, we observe (i) the appearance of a negatively going holelike trap $\mathrm{H}_{1}$ at $510 \mathrm{~K}$ in the low-[C]
SBD and a holelike trap $\mathrm{H}_{2}$ at $\mathrm{T}>550 \mathrm{~K}$ in the high-[C] SBD; and ii) an increase in traps $\mathrm{A}_{\mathrm{x}}$ and $\mathrm{A}_{1}$ in the low-[C] sample and $A_{1}$ and $A_{2}$ in the high-[C] sample, which is due to an increase in the detection volume. As $U_{P}$ further increases from -3 to $1 \mathrm{~V}$, corresponding to detection across the 2DEG channel, we observe i) a significant increase in $\mathrm{H}_{1}$ in the low-[C] SBD and $\mathrm{H}_{2}$ in high-[C] SBD $\left(\mathrm{H}_{2}\right.$ had not peaked before the upper temperature limit was reached); (ii) almost no change in the electron traps $\left(A_{x}\right.$ and $\left.A_{1}\right)$ in the low-[C] SBD and $\left(\mathrm{A}_{1}\right.$ and $\left.\mathrm{A}_{2}\right)$ in the high-[C] SBD; and (iii) a significant decrease in the electron traps, $\mathrm{A}_{2}$ in the low-[C] SBD and $\mathrm{A}_{3}$ in the high-[C] SBD, which is due to the influence of increased negatively going $\mathrm{H}_{1}$ and $\mathrm{H}_{2}$ in the respective SBDs. The results mentioned above clearly indicate the existence of holelike traps in the 2DEG or interface region in the $\mathrm{AlGaN} / \mathrm{GaN}$ heterostructures, with different trap species $\left(\mathrm{H}_{1}\right.$ or $\left.\mathrm{H}_{2}\right)$ in wafers with different $[\mathrm{C}]$ in the $\mathrm{GaN}$ buffer layer. Holelike traps have been previously reported for AlGaN/GaN HFETs using current or conductance DLTS techniques. ${ }^{6}$ In Ref. 6 , two holelike traps $(0.29$ and $0.55 \mathrm{eV})$ were attributed to surface states of the HFET, since they became small in devices passivated with $\mathrm{Si}_{3} \mathrm{~N}_{4}$. The two deep holelike traps $\left(\mathrm{H}_{1}\right.$ and $\left.\mathrm{H}_{2}\right)$, found here in passivated SBDs which increase near the 2DEG channel, are believed to be traps located at $\mathrm{AlGaN} / \mathrm{GaN}$ heterointerface, rather than on the AlGaN surface between the Schottky and Ohmic contacts. Such heterointerface states have recently attracted attention. For example, a planar Pt/AlGaN/GaN SBD was characterized by $\mathrm{C}-\mathrm{V}$ and DLOS measurements, and compared to a reference $\mathrm{Pt} / \mathrm{GaN}$ :Si SBD. ${ }^{5}$ Two specific deep levels, at $\sim 1.70$ and $\sim 2.08 \mathrm{eV}$ below the conduction band, were reported, with the $1.70 \mathrm{eV}$ level behaving as a hole trap as well as an electron trap. From the diode bias dependence of the steady-state photocapacitance, these levels were believed to stem from the 2DEG region at the AlGaN/GaN heterointerface. Whether or not the $1.70 \mathrm{eV}$ level has a connection with our holelike traps $\mathrm{H}_{1}$ or $\mathrm{H}_{2}$ requires further study.

To determine the activation energy of the dominant holelike trap $\mathrm{H}_{1}$ in the low-[C] SBD and the electron trap $\mathrm{A}_{1}$ in the high-[C] SBD, DLTS spectra were measured using values of $\mathrm{T}_{\mathrm{W}}$ from 102.4 to $819.2 \mathrm{~ms}$. As shown in Figs. 4(a) and 4(b), the DLTS peaks of these traps shift with $\mathrm{T}_{\mathrm{W}}$. In our digital DLTS system, the Arrhenius plot for a given trap can be obtained by using the "maximum evaluation" method. This method is based on an analysis of the peak temperature of a given trap obtained from the different Fourier components of the capacitance transient. From these Arrhenius plots, shown in the insets of Figs. 4(a) and 4(b), values of the activation energy and capture cross section were determined to be $1.24 \mathrm{eV}$ and $5 \times 10^{-12} \mathrm{~cm}^{2}$ for the holelike trap $\mathrm{H}_{1}$ and $0.99 \mathrm{eV}$ and $1.5 \times 10^{11} \mathrm{~cm}^{2}$ for the electron trap $\mathrm{A}_{1}$. These values are similar to those observed for trap $A_{1}$, previously reported by our laboratory for $\mathrm{AlGaN} / \mathrm{GaN}$ SBDs from other source. ${ }^{3}$ Activation energy of $0.9 \mathrm{eV}$ for trap $\mathrm{A}_{\mathrm{x}}$ was found in AlGaN/GaN SBDs studied recently in our laboratory. ${ }^{9}$ Trap $\mathrm{A}_{2}$ with activation energy of $1.2 \mathrm{eV}$ was observed in bulklike $\mathrm{GaN}$ grown by hydride vapor phase epitaxy and irradiated with $0.4 \mathrm{MeV}$ electrons, and in the electron-irradiated 

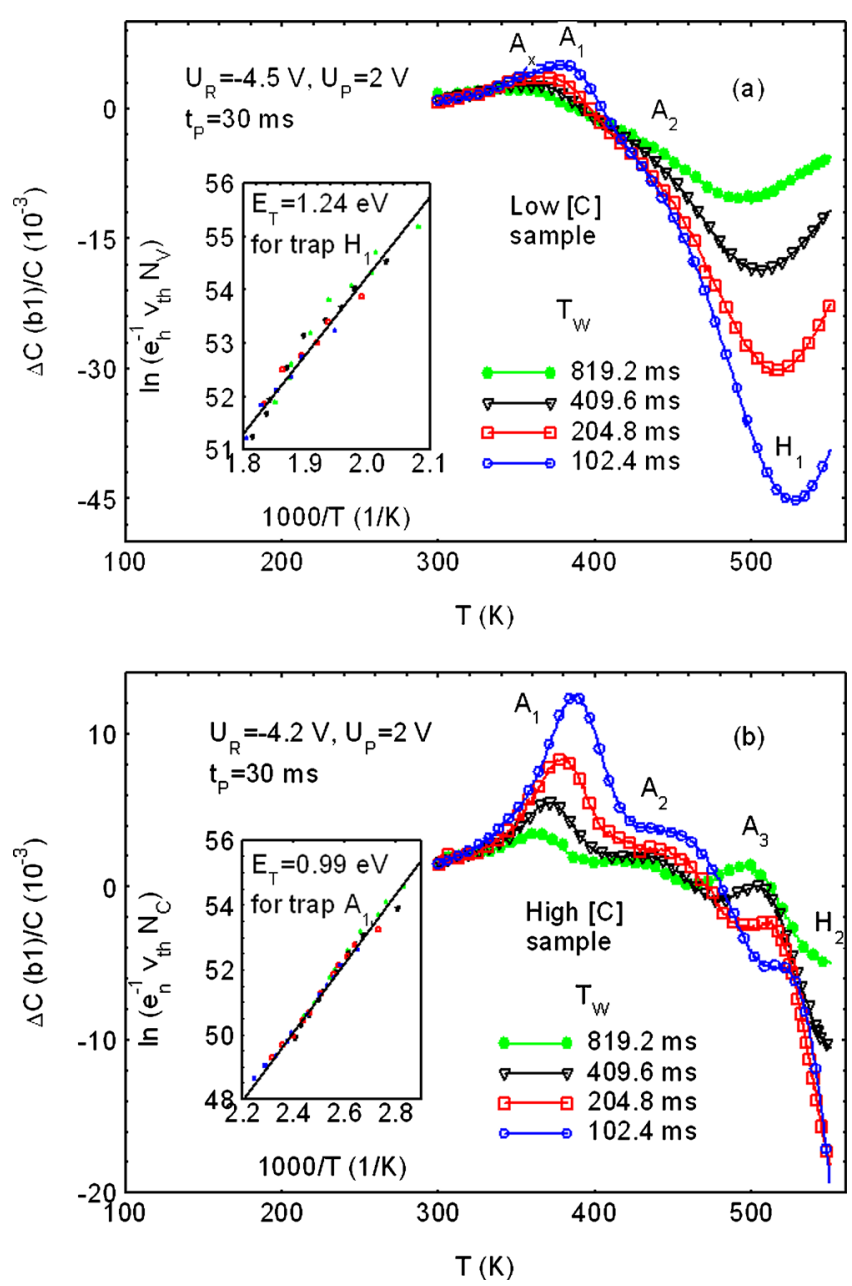

FIG. 4. (Color online) DLTS spectra as a function of transient periods $\left(\mathrm{T}_{\mathrm{W}}\right)$ from 102.4 to $819.2 \mathrm{~ms}$ : (a) trap $\mathrm{H}_{1}$ in the low [C] sample and (b) trap $\mathrm{A}_{1}$ in the high [C] sample. Arrhenius plots of $\ln \left(\mathrm{e}_{\mathrm{h}, \mathrm{n}}^{-1} \mathrm{v}_{\mathrm{th}} \mathrm{N}_{\mathrm{C}, \mathrm{V}}\right)$ for $\mathrm{H}_{1}$ and $\mathrm{A}_{1}$ are shown in the respective insets.

AlGaN/GaN SBDs as well. ${ }^{9}$ Since two traps, trap E $(0.16 \mathrm{eV}$, related to the $\mathrm{N}$-vacancy) and trap $\mathrm{A}_{2}$, were simultaneously induced by the EI, $\mathrm{A}_{2}$ was tentatively identified as the corresponding $\mathrm{N}$-interstitial. Activation energy for traps $\mathrm{A}_{3}$ and $\mathrm{H}_{2}$ cannot be accurately determined. Because of their peak temperatures at $\mathrm{T}>500 \mathrm{~K}$, they must have activation energies higher than $1.2 \mathrm{eV}$, with an estimated value of $\sim 1.3 \mathrm{eV}$ for the $\mathrm{A}_{3}$.

In AlGaN/GaN HFETs grown by MOCVD, the role of carbon with respect to the deep traps responsible for current collapse was studied by photoionization spectroscopy. ${ }^{2}$ From that study, it was found that (i) two deep traps, trap1 at 1.8 $\mathrm{eV}$ (which may be associated with dislocations) and trap2 at $2.85 \mathrm{eV}$ [which is due to a carbon-related defect, from a comparison of its concentration with carbon concentration measured by secondary ion mass spectroscopy (SIMS)], were responsible for the current collapse; (ii) there was a substantial increase in concentration of the $2.85 \mathrm{eV}$ trap at the lowest growth pressure (65 Torr), which corresponds to higher carbon incorporation and more severe current collapse; and (iii) there was a possible correlation between a deep carbon-related defect (providing a deep acceptor at 0.86 $\mathrm{eV}$ above the valance band) and yellow luminescence (YL) in carbon-doped GaN. As for the carbon-related levels in UID GaN grown by MOCVD, we previously used thermally stimulated current (TSC) spectroscopy to study deep centers. ${ }^{10}$ In that case, the sample, with a thickness of $\sim 1.5 \mu \mathrm{m}$ and total dislocation density of $\sim 5 \times 10^{9} \mathrm{~cm}^{-2}$, had resistivity of about $10^{10} \Omega \mathrm{cm}$. At least, six TSC traps peaked at $80 \mathrm{~K}<\mathrm{T}<400 \mathrm{~K}$, i.e., trap $\mathrm{B}(0.63 \mathrm{eV})$, trap $\mathrm{B}_{\mathrm{x}}$ $(0.51 \mathrm{eV}), \mathrm{C}_{1}(0.44 \mathrm{eV}), \mathrm{C}(0.32 \mathrm{eV}), \mathrm{D}(0.23 \mathrm{eV})$, and $\mathrm{E}$ $(0.16 \mathrm{eV})$, were observed. Interestingly, these TSC traps are all similar to DLTS traps observed in various types of $n-G a N$, except for $B_{x}$. In a subsequent TSC study of carbondoped semi-insulating GaN, grown by ammonia-based molecular beam epitaxy $(\mathrm{MBE})$, trap $\mathrm{B}_{\mathrm{x}}(0.50 \mathrm{eV})$ was found to dominate in the high-carbon sample $\left([\mathrm{C}]=8 \times 10^{18} \mathrm{~cm}^{-3}\right)$ and was tentatively assigned to $\mathrm{C}_{\mathrm{Ga}} \cdot{ }^{11}$ The impact of carbon on trap states in n-type $\mathrm{GaN}$ grown by MOCVD was also studied by both DLTS and DLOS. ${ }^{12}$ From a comparison of the DLOS measurements on low-pressure grown codoped $\mathrm{GaN}: \mathrm{C}: \mathrm{Si}$ and atmospheric-pressure grown UID GaN, two deep levels, at 1.35 and $3.28 \mathrm{eV}$ below the conduction band, were observed to have a direct relation with excess carbon incorporation. The $1.35 \mathrm{eV}$ and $3.28 \mathrm{eV}$ levels were believed to be due to $\mathrm{C}_{\mathrm{I}}$ (interstitial) and $\mathrm{C}_{\mathrm{N}}$ (substitutional) defects, respectively. Thus, from these studies, carbon-related centers in MOCVD-grown UID GaN might include traps at $0.50 \mathrm{eV}$ $\left(\mathrm{B}_{\mathrm{x}}\right), 2.85 \mathrm{eV}$ (trap2), $1.35 \mathrm{eV}, 3.28 \mathrm{eV}$, and $2.2 \mathrm{eV}(\mathrm{YL})$ centers. In this study, many deep electron and holelike traps were observed. At present, we do not know their correlation with these reported carbon-related centers. However, the trap $\mathrm{A}_{3}(\sim 1.3 \mathrm{eV})$ in the high [C] sample could be correlated with the $\mathrm{C}_{\mathrm{I}}$-related $1.35 \mathrm{eV}$ level.

DLTS spectra, measured as a function of filling pulse width $\left(\mathrm{t}_{\mathrm{p}}\right)$, for the low-[C] and high-[C] SBDs are presented in Figs. 5(a) and 5(b), respectively. From the two figures, we can see that both traps $\mathrm{H}_{1}$ in the low-[C] SBD and $\mathrm{A}_{1}$ in the high-[C] SBD increase with increasing $t_{p}$, exhibiting logarithmic dependence, as shown in the inset figures. This kind of dependence, as reported previously for trap $A_{1}$ in the MOCVD-grown AlGaN/GaN heterostructure, ${ }^{3}$ is an indication of the association of both traps $\mathrm{H}_{1}$ and $\mathrm{A}_{1}$ in $\mathrm{AlGaN} /$ $\mathrm{GaN}$ with extended defects, such as threading dislocations. Traps $A_{x}$ and $A_{1}$ in the low-[C] SBD and traps $A_{2}$ and $\mathrm{H}_{2}$ (only half of $\mathrm{H}_{2}$ was observed) in the high-[C] SBD also appear to be associated with extended defects, since their DLTS signals show a strong $t_{p}$ dependence. Actually, $A_{x}$ was also reported to be related to extended defects in a previous study. ${ }^{9}$ Unfortunately, nothing can be judged for trap $A_{3}$, since its peak is pulled down with increasing $t_{p}$, due to an increase in negatively going signal for the holelike trap $\mathrm{H}_{2}$. Thus, in the two SBDs, almost all of observed traps, which are believed to be related to either point defects (e.g., $\mathrm{N}$-interstitials) or impurities (e.g., carbon), are evidently associated with extended defects, such as threading dislocations.

The capture kinetics and trapping behavior of dislocation-related electron traps have been well studied in many material systems by using DLTS. These traps often show both a logarithmic dependence of DLTS peak height on filling pulse width $\left(t_{\mathrm{p}}\right)$, and broadened asymmetrical peaks 

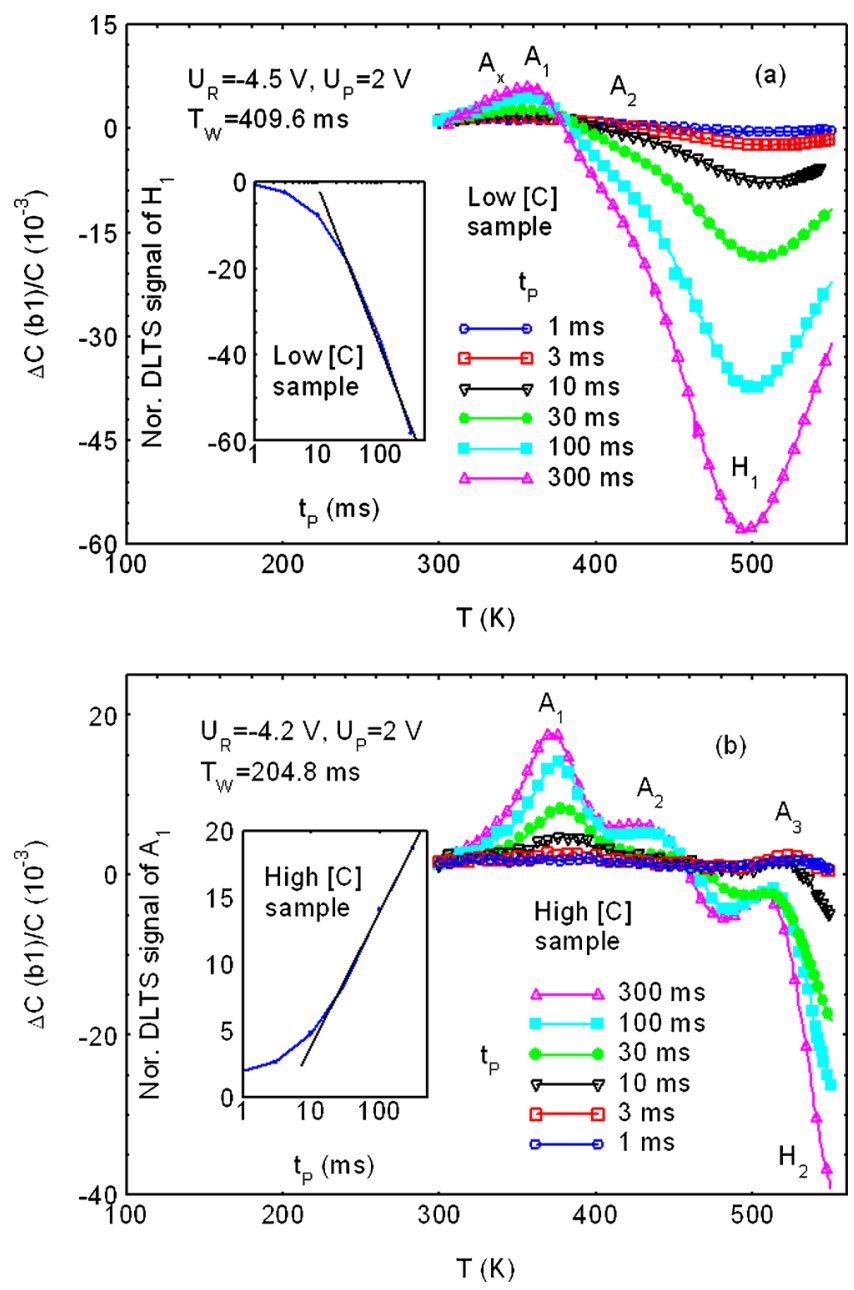

FIG. 5. (Color online) DLTS spectra as a function of filling pulse width $\left(t_{\mathrm{P}}\right)$ from 1 to $300 \mathrm{~ms}$. Logarithmic dependence of normalized DLTS signal with $t_{P}$ for (a) trap $\mathrm{H}_{1}$ in the low-[C] sample and (b) trap $\mathrm{A}_{1}$ in the high-[C] sample are shown in the respective insets.

(when the rate window is kept unchanged). A model of the time-dependent capture barrier associated with extended line defects, i.e., with the capture barrier height proportional to the number of electrons already captured, has been proposed to explain the anomalous electron capture behavior. ${ }^{13}$ Furthermore, as pointed out by Hierro et al. ${ }^{14}$ such a capture kinetics for trap $\mathrm{E}(0.91)$ with activation energy of $0.91 \mathrm{eV}$ in MBE-grown $n-G a N$ [which is close to our $A_{x}$ (Ref. 9)] can be explained as arising from either point defects arranged along a threading dislocation or from the threading dislocation core itself. Since point defects will generate a localized state in the bandgap whereas threading dislocation cores will create a band of states, the trap occupancy will differ. In the former case, the DLTS peak temperature would be independent of $t_{\mathrm{P}}$, whereas in the latter case, it shifts to higher temperatures with decreasing $t_{\mathrm{P}}$, which was observed for their trap $\mathrm{E}(0.91)$ and our traps $\mathrm{H}_{1}$ and $\mathrm{A}_{1}$ [see Figs. 5(a) and 5(b)]. Capture kinetics for a trap associated with extended defects also leads to significant change in its DLTS peak height with changing $\mathrm{T}_{\mathrm{W}}$ (i.e., rate window) or peak temperature (when $t_{P}$ is kept unchanged), as observed in Figs. 4(a) and 4(b). The reason for this change is usually not due to the temperature dependence of the capture cross section but rather due to the relative change in the ratio $t_{P} / T_{W}$, as set by the DLTS measurement conditions. ${ }^{13}$ For major traps (such as traps $\mathrm{A}_{1}, \mathrm{~A}, \mathrm{~B}, \mathrm{C}$, and $\mathrm{D}$ ) in freestanding $\mathrm{GaN}$, with low dislocation density $\left(5 \times 10^{6} \mathrm{~cm}^{-2}\right)$, almost no change in the DLTS peak height is observed with change in either filling pulse width or rate window, which indicates that these traps are not associated with extended defects, but related to isolated point defects, which are not arranged along dislocations. $^{13}$

\section{SUMMARY AND CONCLUSIONS}

Now, we can summarize the differences and similarities of traps in AlGaN/GaN heterostructures, for GaN buffer layers containing different concentrations of carbon. In the low-[C] sample, the major electron traps are $A_{x}, A_{1}$, and $A_{2}$, and a holelike trap $\mathrm{H}_{1}$ is observed at $\sim 510 \mathrm{~K}$. In the high-[C] sample, the major electron traps are $\mathrm{A}_{1}, \mathrm{~A}_{2}$, and $\mathrm{A}_{3}$, and a holelike trap $\mathrm{H}_{2}$ is found at $\mathrm{T}>550 \mathrm{~K}$. Electron traps show lower density in the low-[C] sample than in the high-[C] sample. However, for both samples, only electron traps can be observed in the detection region close to the GaN buffer layer, and the holelike traps can be detected only near the 2DEG or interface region of AlGaN/GaN. All traps, both electron and holelike, exhibit a strong dependence on filling pulse width, indicating their association with extended defects. These results are consistent with an early study on the relationship of $\mathrm{GaN}$ resistivity to film microstructure and impurity compensation by Wickenden et $a l^{7}$ It was concluded from that study that (i) with increasing growth pressure, the GaN films exhibit increasing grain size, decreasing density of threading edge dislocations, decreasing carbon and oxygen concentrations, and decreasing resistivity, and (ii) threading edge dislocations play a major role in the compensation mechanism of GaN, with carbon impurity segregation at or near the threading dislocations providing compensating acceptor states. In this study, we observe that with increasing growth pressure of GaN buffer layers, AlGaN/ $\mathrm{GaN}$ heterostructures exhibit a variety of electron traps in the GaN buffer layer, holelike traps near the AlGaN/GaN interface, decreasing dislocation-related electron traps, and decreasing carbon concentration. Further study on the impact of these traps on HFET device performance, such as current collapse and reliability, is needed. A good correlation between current collapse of AlGaN/GaN HFET wafers grown on silicon substrates and YL $(\sim 2.2 \mathrm{eV})$ intensity has been found by scientists at Toshiba Corp. ${ }^{15}$ It is necessary to further study correlation between the deep holelike traps $\left(\mathrm{H}_{1}\right.$ and $\left.\mathrm{H}_{2}\right)$ and the YL. In writing this paper, a study about effect of $\mathrm{GaN}$ buffer layer growth pressure on the device characteristics of AlGaN/GaN HEMTs on $\mathrm{Si}$ was published. ${ }^{16}$ In that study, it was found that the formation of highly resistive buffer with [C] as high as $3.8 \times 10^{17} \mathrm{~cm}^{-3}$ (for $\mathrm{GaN}$ grown at 200 Torr pressure) leads to reduced buffer leakage over one order of magnitude and enhanced breakdown voltage of $425 \mathrm{~V}$ for a HEMT with gate-drain spacing of $4 \mu \mathrm{m}$. However, unlike samples grown at atmospheric 
pressure, the presence of unintentional $\mathrm{C}$ in the semiinsulating $\mathrm{GaN}$ degraded the channel conduction and resulted in severe current collapse.

\section{ACKNOWLEDGMENTS}

We would like to thank Dr. Donald Dorsey for encouragement and support, and Tim Cooper for Hall-effect measurements. This work was performed by the AFRL-lead National High Reliability Electronics Virtual Center (HiREV). The work of Z.-Q.F., B.C., and D.C.L. was directly supported by AFRL's Materials \& Manufacturing Directorate under Contract No. FA8650-06-D-5401.

${ }^{1}$ S. C. Binari, K. Ikossi, J. A. Roussos, W. Kruppa, D. Park, H. B. Dietrich, D. D. Koleske, A. E. Wickenden, and R. L. Henry, IEEE Trans. Electron Devices 48, 465 (2001).

${ }^{2}$ P. B. Klein, S. C. Binari, K. Ikossi, A. E. Wickenden, D. D. Koleske, and R. L. Henry, Appl. Phys. Lett. 79, 3527 (2001).

Z.-Q. Fang, D. C. Look, D. H. Kim, and I. Adesida, Appl. Phys. Lett. 87, 182115 (2005).

${ }^{4}$ A. Armstrong, A. Chakraborty, J. S. Speck, S. P. DenBaars, U. K. Mishra, and S. A. Ringel, Appl. Phys. Lett. 89, 262116 (2006).

${ }^{5}$ Y. Nakano, Y. Irokawa, and M. Takeguchi, Appl. Phys. Express 1, 091101
(2008).

${ }^{6}$ T. Mizutani, T. Okino, K. Kawada, Y. Ohno, S. Kishmoto, and K. Maezawa, Phys. Status Solidi A 200, 195 (2003).

${ }^{7}$ A. E. Wickenden, D. D. Koleske, R. L. Henry, M. E. Twigg, and M. Fatemi, J. Cryst. Growth 260, 54 (2004).

${ }^{8}$ P. Kordoš, D. Donoval, M. Florovič, J. Kováč, and D. Gregušová, Appl. Phys. Lett. 92, 152113 (2008).

${ }^{9}$ Z.-Q. Fang, G. C. Farlow, B. Claflin, D. C. Look, and D. S. Green, J. Appl. Phys. 105, 123704 (2009).

${ }^{10}$ Z.-Q. Fang, B. Claflin, D. C. Look, T. H. Myers, D. D. Koleske, A. E. Wickenden, and R. L. Henry, GaN and Related Alloys-2002, MRS Symposia Proceedings No. 743 (Materials Research Society, Pittsburgh, 2005), p. 749.

${ }^{11}$ Z.-Q. Fang, D. C. Look, B. Claflin, S. Haffouz, H. Tang, and J. Webb, Phys. Status Solidi C 2, 2757 (2005).

${ }^{12}$ A. Armstrong, A. R. Arehart, B. Moran, S. P. DenBaars, U. Mishra, J. S. Speck, and S. A. Rengel, Appl. Phys. Lett. 84, 374 (2004).

${ }^{13}$ Z.-Q. Fang, D. C. Look, and L. Polenta, J. Phys.: Condens. Matter 14, 13061 (2002).

${ }^{14}$ A. Hierro, A. R. Arehart, B. Heying, M. Hansen, J. S. Speck, U. K. Mishra, S. P. DenBaars, and S. A. Ringel, Phys. Status Solidi B 228, 309 (2001).

${ }^{15}$ H. Fujimoto, W. Saito, A. Yoshioka, T. Nitta, Y. Kakiuchi, and Y. Saito, CS MANTECH Dig. 5.2 (2008).

${ }^{16}$ J. Selvaraj, S. L. Selvaraj, and T. Egawa, Jpn. J. Appl. Phys., Part 2 48, 121002 (2009). 